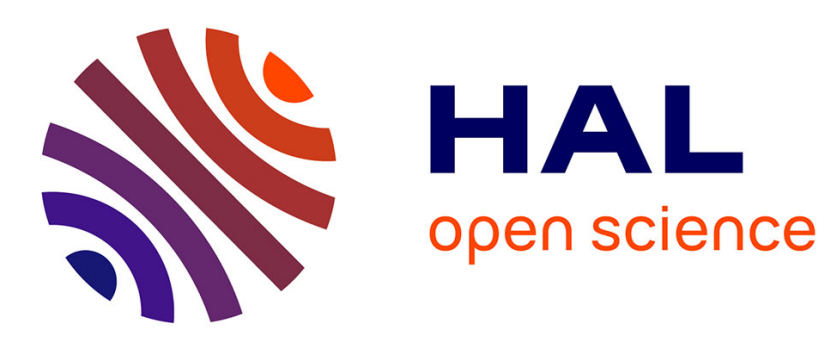

\title{
ON THE FORMATION OF TWINNED PRECIPITATES IN Al-Ge ALLOYS
}

\author{
Joël Douin, U. Dahmen, K. Westmacott
}

\section{To cite this version:}

Joël Douin, U. Dahmen, K. Westmacott. ON THE FORMATION OF TWINNED PRECIPITATES IN Al-Ge ALLOYS. Journal de Physique Colloques, 1990, 51 (C1), pp.C1-809-C1-814. 10.1051/jphyscol:19901126 . jpa-00230035

\section{HAL Id: jpa-00230035 https://hal.science/jpa-00230035}

Submitted on 1 Jan 1990

HAL is a multi-disciplinary open access archive for the deposit and dissemination of scientific research documents, whether they are published or not. The documents may come from teaching and research institutions in France or abroad, or from public or private research centers.
L'archive ouverte pluridisciplinaire HAL, est destinée au dépôt et à la diffusion de documents scientifiques de niveau recherche, publiés ou non, émanant des établissements d'enseignement et de recherche français ou étrangers, des laboratoires publics ou privés. 
ON THE FORMATION OF TWINNED PRECIPITATES IN AI-GE ALLOYS

\author{
J. DOUIN", U. DAHMEN and K.H. WESTMACOTT \\ National Center for Electron Microscopy, MCSD, Lawrence Berkeley \\ Laboratory, University of California Berkeley, California 94720, U.S.A. \\ * Now at Institut de Génie Atomique, Département de Physique, Ecole \\ Polytechnique Fédérale de Lausanne, PHB-Ecublens, CH-1004 Lausanne, \\ Switzerland
}

Résumé - Une meilleure compréhension de la précipitation de Ge dans Al a été obtenue par une utilisation systématique de la microscopie en haute résolution. La formation des aiguilles maclées quion observe le long de $<100\rangle_{\mathrm{Al}}$ et $\langle 110\rangle_{\mathrm{Al}}$ peut être reliée à l'existence de quelques configurations atomiques particulières. On montre aussi que le maclage sert à réduire le nombre de lacunes utilisées lors de la nucléation des précipités.

Abstract - Atomic resolution microscopy has been used systematically to obtain a better understanding of Ge precipitation in Al. The formation of the observed twinned $\langle 100\rangle_{\mathrm{Al}}$ and $\langle 110\rangle_{\mathrm{Al}}$ needles can be related to the existence of a few special configurations. It is shown that twinning serves during nucleation to reduce the need of vacancies.

\title{
1 - INTRODUCTION
}

A solid state precipitation reaction is a convenient method for forming heterophase interfaces in materials. Since the precipitating phase nucleates and grows in the bulk of a supersaturated solid solution a clean contamination-free condition for the interface formation is assured.

Aluminum-germanium is a particularly interesting system for study because many different orientation precipitate morphologies develop and several different orientation relationshipsare found. It also provides metal/semi-conductor interfaces. Some of the factors important in determinating the shapes, orientation relationships, internal and interface structures can be deduced from high resolution studies of the structure of needle, rod and lath precipitates observed endon.

\section{2 - EXPERIMENTAL}

After ageing for a week at $550^{\circ} \mathrm{C}, 3 \mathrm{~mm}$ discs of an alloy of nominal composition $\mathrm{Al}-1.1 \%$ at. Ge were quenched to $-60^{\circ} \mathrm{C}$ in order to create vacancies supersaturation. Precipitation was ensured either by bulk or in-situ ageing for $4 \mathrm{~h}$ between $220^{\circ} \mathrm{C}$ and $260^{\circ} \mathrm{C}$. High resolution imaging of precipitate cross-sections was performed using the Berkeley Jeol ARM 1000 operating at $800 \mathrm{kV}$.

\section{3 - RESULTS}

The overall precipitate morphology and distribution in quench/aged $\mathrm{Al}-\mathrm{Ge}$ is shown in Fig.1. Needles can be found either parallel to the $\langle 100\rangle_{\mathrm{Al}}$ or $\langle 110\rangle_{\mathrm{Al}}$ axis. The influence of vacancy supersaturation on the type of precipitate nucleated has been directly examined in thin foil experiment $/ 1 /$. It has been observed that in thin regions of a foil where substantial loss of vacancies occurs, needles are the predominant morphology nucleated. Among all the precipitate configurations, multiply-twinned precipitates (MTP) is the most frequent one. 
Fig. 1: A typical micrograph from a quench/aged $\mathrm{Al}-1.1 \%$ $\mathrm{Ge}$ alloy shows long needle precipitates lying along $<100\rangle_{\mathrm{Al}}$ directions.

Figure 2 shows a high resolution micrograph of a typical -example of such a MTP. Such images simultaneously give information on the shape, substructure, orientation relationship and interface structure of precipitates. This Ge particle exhibits one set of parallel twins and an interface with the $\mathrm{Al}$ matrix that is faceted on $\{111\}_{\mathrm{Ge}} /\{100\}_{\mathrm{Al}}$ and $\{111\}_{\mathrm{Ge}} /\{310\}_{\mathrm{Al}}$ planes.
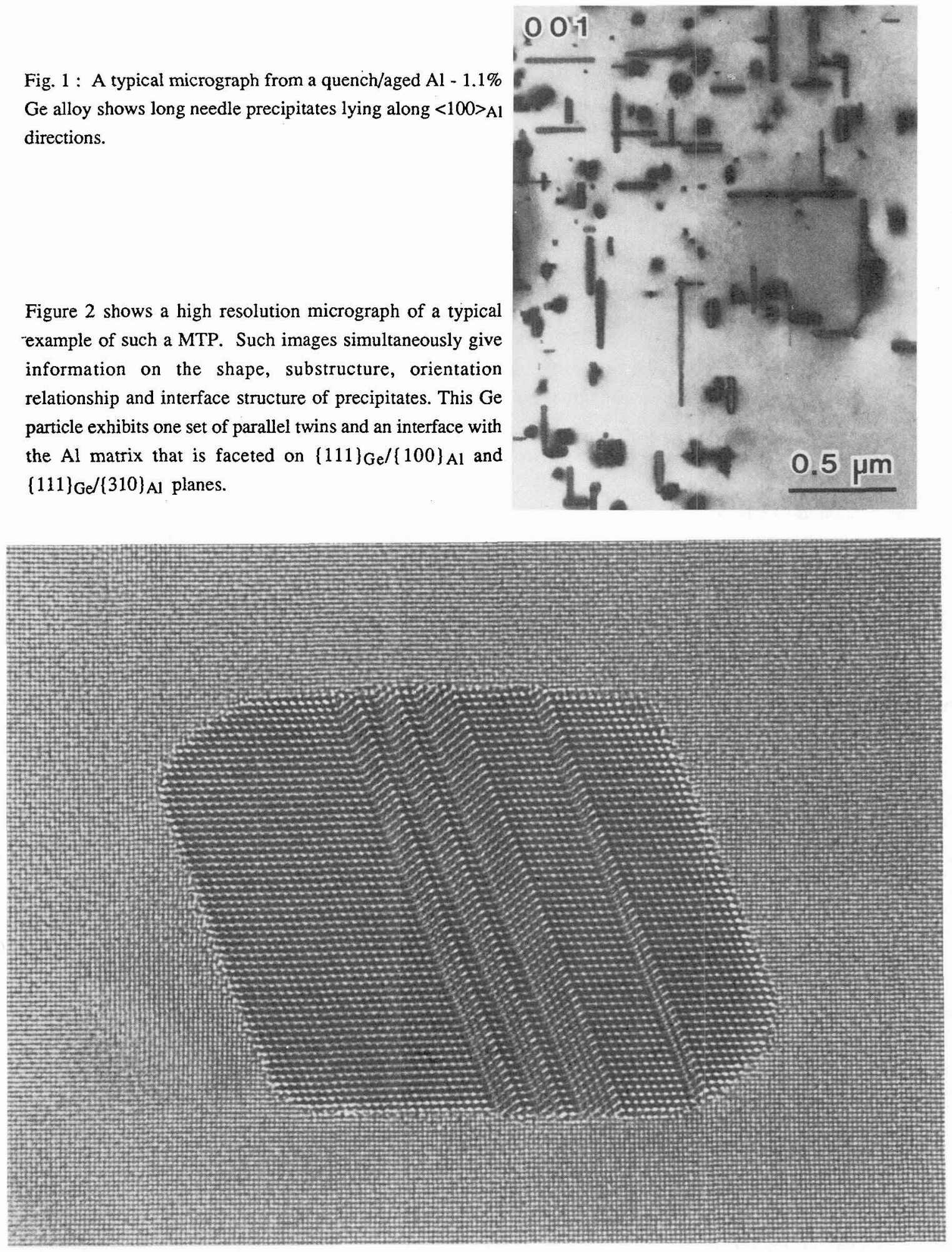

Fig. 2 : High resolution micrograph in which a needle is observed in cross-section. The axis of the needle is $<110>\mathrm{Ge}$ parallel to $a<100\rangle_{\text {AI }}$ direction. No relaxation into a dislocation structure is apparent at either type of interface. 
As already reported $/ 1 /$, the faceting of the precipitate occurs mostly on $\{111\}$ Ge planes and usually exhibits contrats consistent with twinning or a change in stacking sequence at the interface beeween aluminum and germanium.

When twinning occursin different planes sharing a common $<110\rangle$ direction, five internal twin-related segments are found. Figure 3 (a) shows a high resolution micrograph of a cross-section of a multiply-twinned precipitate found in a bulk-aged sample. The axis of the needle is $\langle 110\rangle_{\mathrm{Ge}}$ parallel to a $\langle 100\rangle_{\mathrm{Al}}$ direction. Since the five twins converge exactly on the same point, the intersection area has a special crystallography : a model of this configuration is shown in Fig. 3 (c) and the corresponding simulation in Fig. 3 (d). The twins meet in a common center imaged as a five-member ring of (black) Ge atom pairs. This kind of ring has already been observed in materials with diamond or face centered cubic structure, e.g. $/ 2,3 /$.
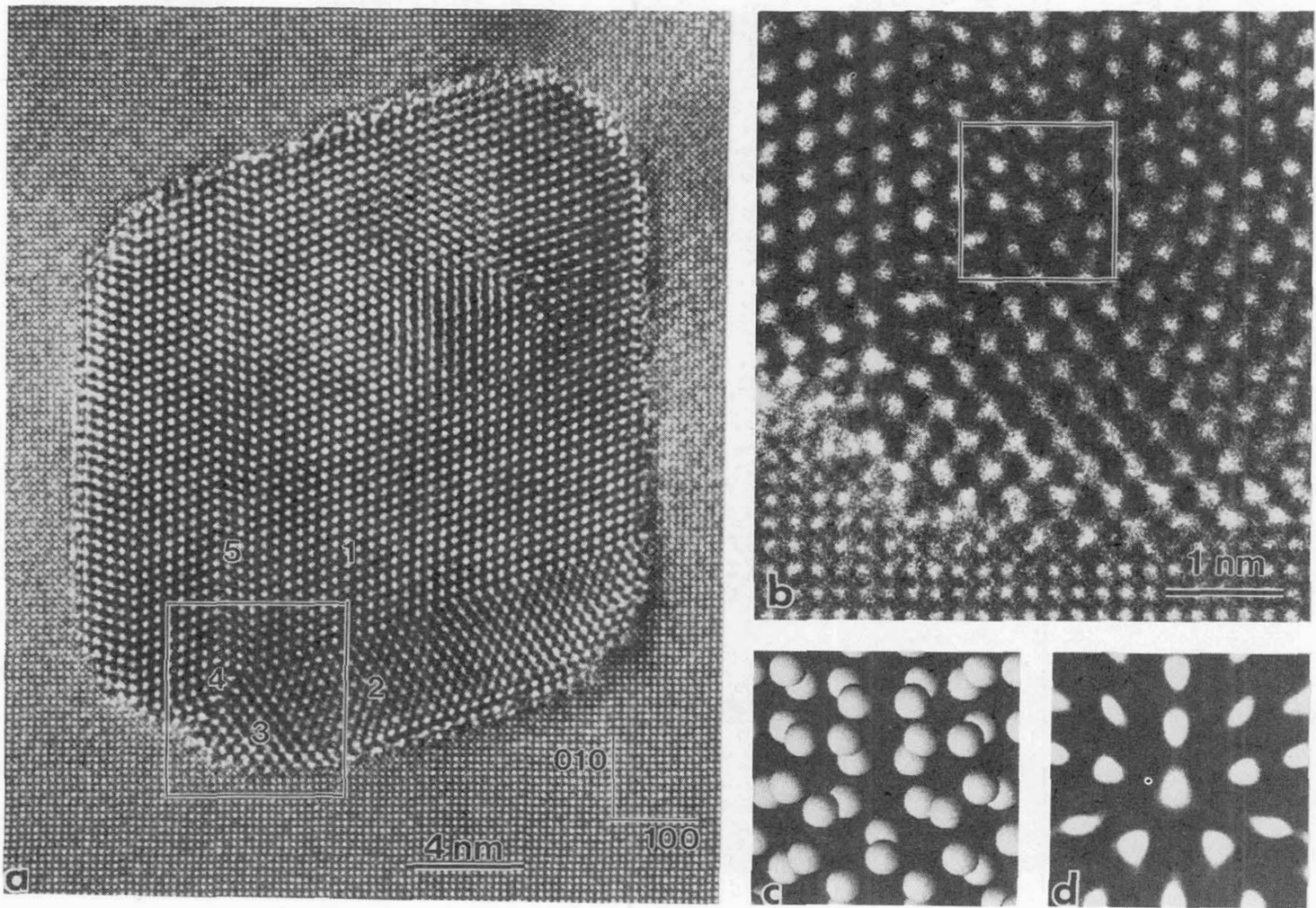

Fig. 3 : Bright field micrograph showing the morphology of Ge precipitate in a bulk-aged sample. Note the aligment along the $<100>$ direction in $\mathrm{Al}$ (for the simulation (d), defocus $=-80 \mathrm{~nm}$, thickness $=5 \mathrm{~nm}$ ). 
Due to the obligation to accomodate the $7.5^{\circ}$ gap left by five twin segments enclosing an angle of $70.5^{\circ}$ each $\left(352.5^{\circ}\right.$ ), pentagonally-twinned particles are usually found to be asymmetrical. However it is possible to find regular particle with a pentagonal symmetry (fig. 4).

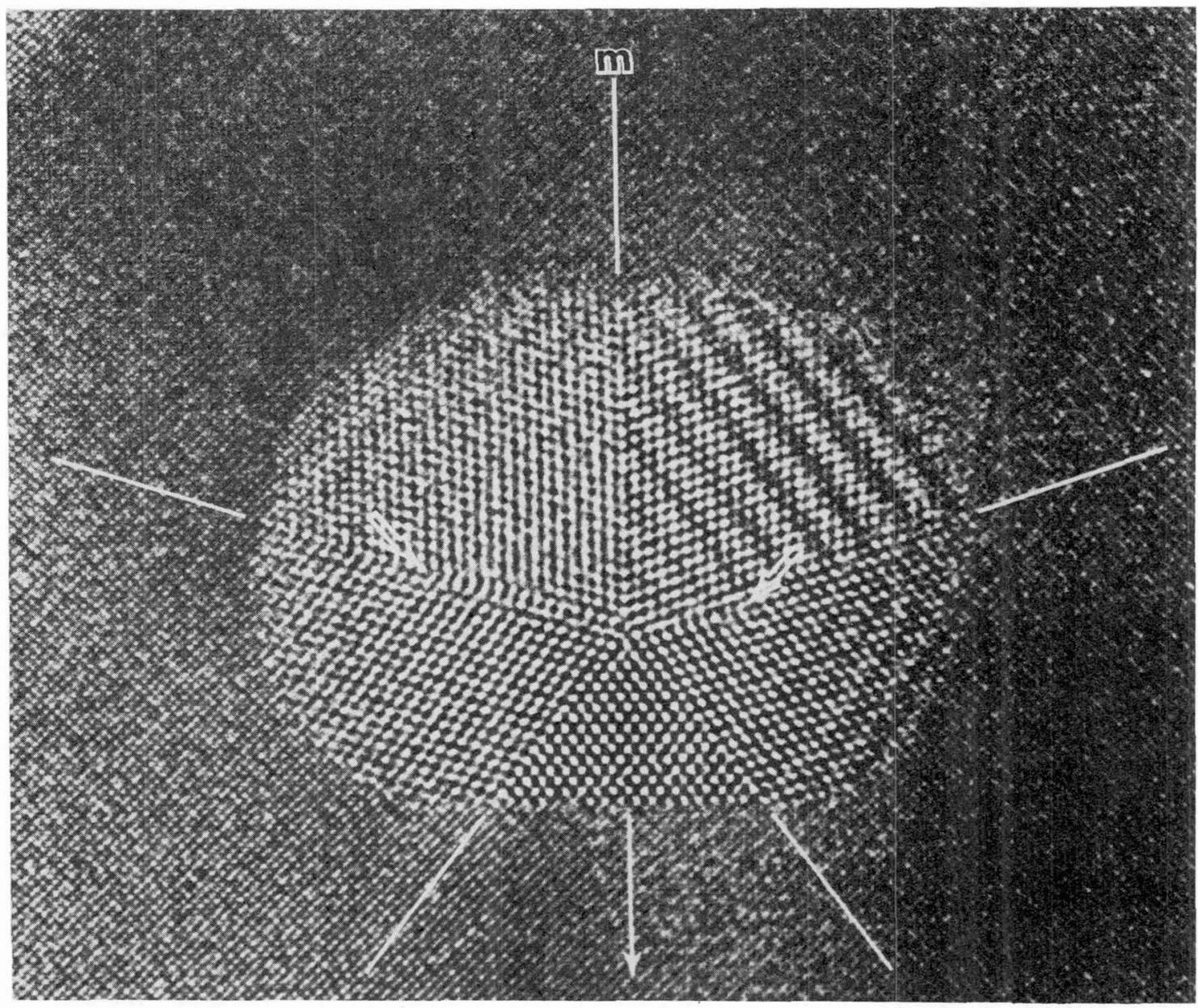

Fig. 4 : Ge precipitate with regular arrangement of five twin segments meeting at a common center. The vertical mirror plane indicated by a line (m) is shared by the $\mathrm{Al}$ matrix, the triangular twin segment at the bottom of the Ge particle and the entire particle morphology, including the extra half planes inserted at the inclined twin boundaries to relieve the $7.5^{\circ}$ gap. Precipitates with such a high degree of perfection in the arrangement of internal defects are unusual. 
Fig. 5 : High resolution micrograph of a $<110\rangle_{\text {Al }}$ needle with the so-called "mushroom" configuration. The head part appears to have a pseudo five-fold symmetry.

In an analogous manner to $\langle 100\rangle_{\mathrm{A} 1}$ needles, $\langle 110\rangle_{\text {Al }}$ needles also display multiply-twinned morphology. Figure 5 is an example of such a precipitate. In the enlargement in fig.5 (b), the convergence of the five twin segments is clearly visible.


\section{4 - VACANCIES AND TWINNING IN NUCLEATION}

In order to accommodate the large disparity in the atomic volumes of aluminun and germanium ( $16.6 \AA^{3}$ and $22.6 \AA^{3}$ respectively), precipitation and growth need an excessof vacancies, usually introduced by quenching, e.g. /4/. The ease of nucleation will be then proportional to the concentration of vacancies or at the least the need a particular configuration has for vacancies. Thus it is postulated that nucleation occurs by a process which tends to reduce the number of vacancies used by increasing the number of $\mathrm{Ge}-\mathrm{Ge}$ bonds per atom . It is possible to construct systematically the possible configurations leading to maximum number of bonds for a given number of atoms in the diamond-cubic structure. As shown in figure 6, when the number of atoms involved is 8,10 or 12 , special closed configurations, or cages, appear which have a higher density of the precipitate nucleus. The first complete nucleus with maximum density is the eight-atoms cage. It consists mainly of six-membered rings with the so-called boat configuration and its extension will lead to a twinned crystal. This is not the case for the second cage in which ten 
Fig. 6 : A plot of the maximum number of bonds possible for a given number of atoms in the diamond -cubic structure is followed by the different atomic configurations corresponding to points on the curve. For some of these, twinning leads to an increased number of bonds per-atom and thus a reduced need for vacancies.

atoms forming six-membered rings constitute the chair configuration known to give rise to an untwinned crystal. The third configuration with

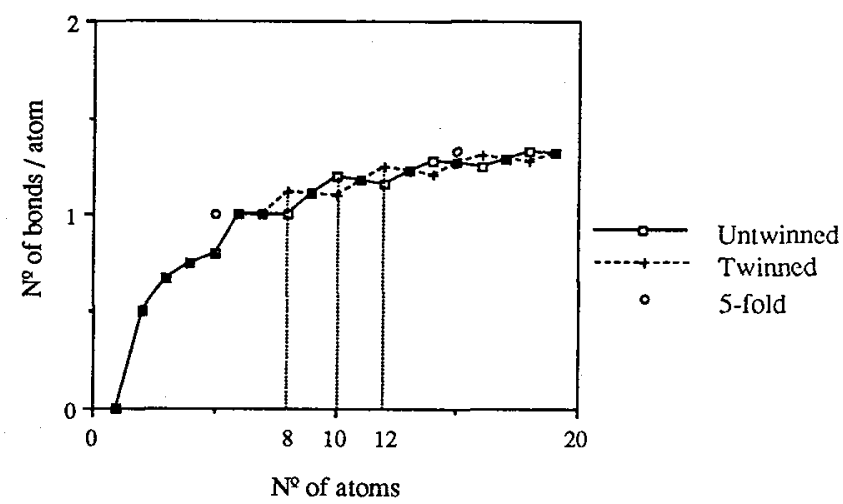
twelve atoms is in fact the continuation of the first configuration with eight atoms, as the fourth is the next step after the ten-atoms cages, and so on. As indicated on fig. 6, the cage resulting from a five-atom ring is only completed for fifteen atoms and doesn't appear to be directly at the origin of particle with fivefold symmetry.

From this considerations, it is clear that twinning serves during nucleation to maximize the number of $\mathrm{Ge}-\mathrm{Ge}$ bonds and thus to reduce the need of vacancies, whereas during growth accidental twinning strongly influences the developing morphologies including the

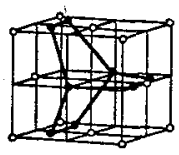
Twinned
$8 \mathrm{Ge}$
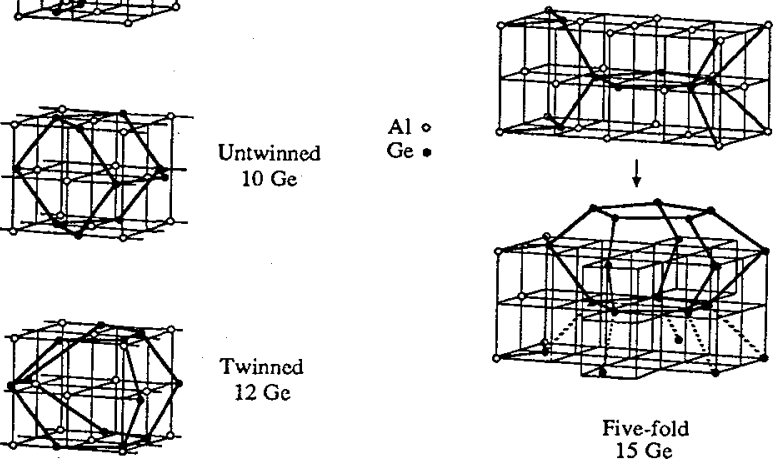
pentagonaly twinned configuration.

\section{5 - CONCLUSIONS}

The present study shows that during precipitation of $\mathrm{Ge}$ in $\mathrm{Al}$, one of the predominant factors for the formation of the nucleus is the demand for vacancies. The configuration which appears to follow this criterium best consists of only eight atoms and invariably leads to the formation of a twinned crystal. Further work is in progress to include rationalization of all observed morphologies in function of the different local vacancy concentrations and different sequences of twinning.

The results also show the convenience of solid state precipitation for study heterophase interfaces in materials.

\section{ACKNOWLEDGMENTS}

This work was supported by the Director, Office of Energy Research, Office of Basic Energy Sciences, Materials Sciences Division of the U.S. Department of Energy under contract No.DE-AC03-76SF00098.

\section{REFERENCES}

11/ K.H. Wesmacott and U. Dahmen, Proc. Phase Transf. Conf., Cambridge, England (1987)

12/ Y. Li and K. Guo, Proc. $3^{\text {th }}$ Chinese-Japanese Elec. Mic. Sem., Hanzhou, China, p.71 (1985).

B) D.A. Jefferson and A.I. Kirkland, Proc. IOP short meet., p.71 (1988).

14/ K.C. Russell, Scripta metall., 3, 313 (1969). 